\title{
Prenatal DNA test raises both hopes and worries
}

$\mathrm{T}$ wenty-one weeks into her pregnancy, Barbara Farlow discovered that her daughter Annie would be born with the genetic disorder trisomy 13 , a chromosomal abnormality — and a label — that would determine her future medical care.

In August 2005, Annie, not yet 3 months old, suffered a respiratory attack and was admitted to hospital. She died within 24 hours. The official cause was "complications of trisomy 13," but Farlow and her husband still don't know the details, despite years of inquiry. They do know, however, that someone issued a do-not-resuscitate order without their consent.

"I feel that the genetic testing ultimately determined her fate," says Farlow, who lives in Mississauga, Ontario. "She was treated as a syndrome. She wasn't treated as a child."

A new prenatal genetic diagnostic test may soon cause a substantial increase in the number of fetuses affixed with "syndrome" labels. The noninvasive test, called chromosomal microarray analysis, allows doctors to detect submicroscopic genetic abnormalities that no other test can find. Advocates of the technology say it is safer, faster and more accurate than invasive diagnostic procedures like amniocentesis. Despite the test's benefits, however, some worry that it will result in a flood of prenatal genetic information of uncertain significance and will lead only to confusion and undue anxiety for expectant parents. Others question whether scientists should even be in the business of cleaning up the gene pool and have evoked the dreaded "E" word: eugenics.

Researchers have been able to diagnose certain genetic conditions, like Down syndrome, in fetuses since the 1960s. This has traditionally been done through karyotyping, which involves extracting cells from amniotic fluid, culturing and staining them in a lab, and examining them under a microscope. In microarray testing, fetal DNA is obtained from a pregnant woman's blood.

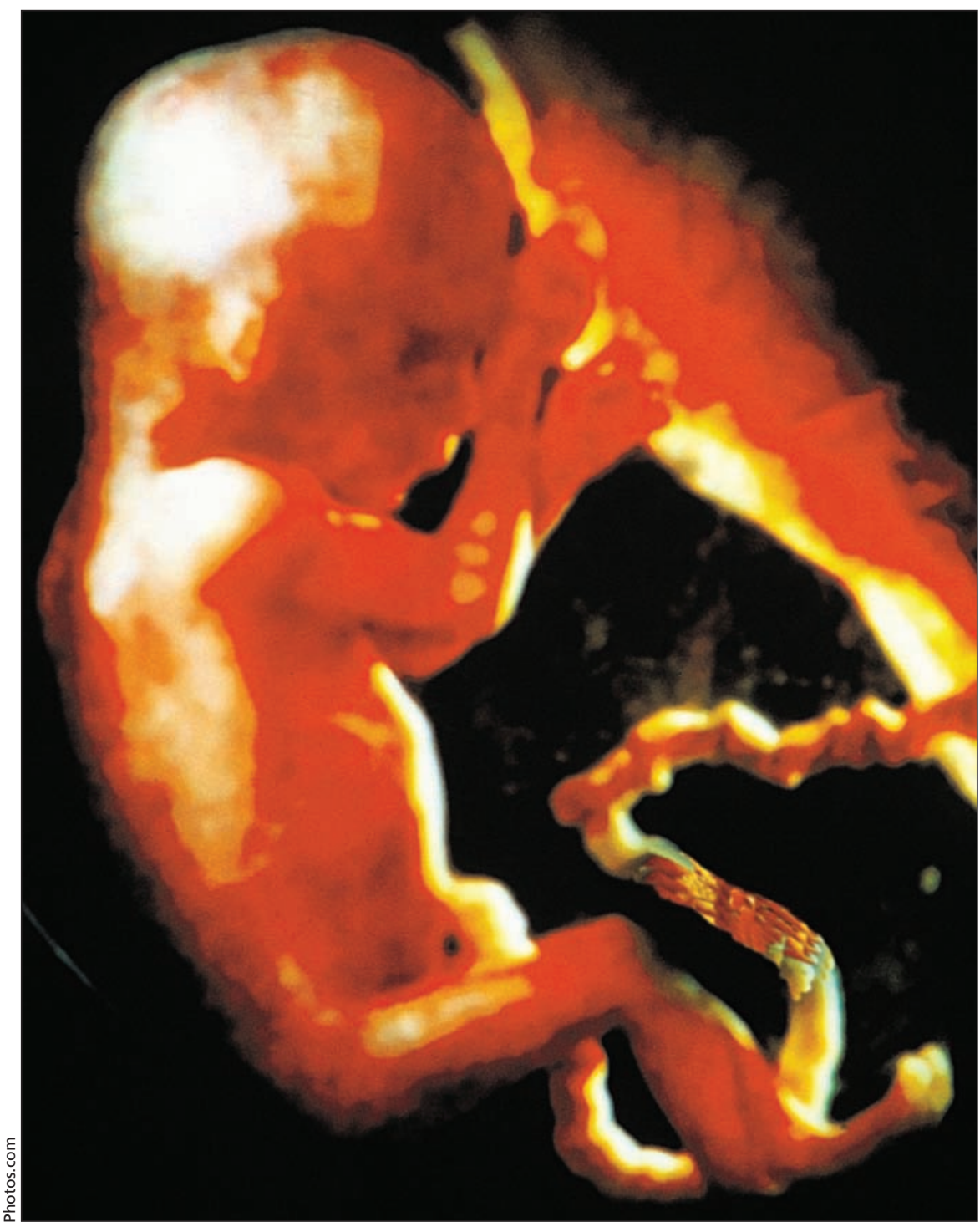

New prenatal diagnostic technology can detect chromosomal anomalies 100 times smaller than those revealed by traditional tests. Advocates say the test is fast, safe and accurate. But some geneticists say ambiguous results will confuse and worry expectant parents. Ethicists wonder if the technology is the start of a "new eugenics."

This eliminates the need to perform amniocentesis, a test that slightly increases the risk of miscarriage. The fetal DNA is compared to control DNA stored on a "gene chip." It detects chromosomal anomalies 100 times smaller than those revealed by traditional tests.

"I think there's going to be a major change in the way prenatal diagnosis is done," says Dr. Arthur Beaudet, chair- man of the Department of Molecular and Human Genetics at Baylor College of Medicine in Houston, Texas. "It's cost-effective if couples are going to terminate. For children born with severe disabilities, their lifelong care is very expensive."

Baylor is one of the few institutions openly promoting microarray testing (others include Signature Genomic Lab- 
oratories in Spokane, Washington, and Emory University in Atlanta, Georgia). No Canadian lab yet offers the test, though doctors can order it from the United States. Beaudet says the biggest barriers to widespread adoption of the test are its cost (US\$1600) and the reluctance of US insurance companies to cover it. "My goal is to get the cost of a new test down to the cost of current tests, and to encourage insurance providers to offer to pay for the new test or the old test, but not both. I hope that's where we are a year from now."

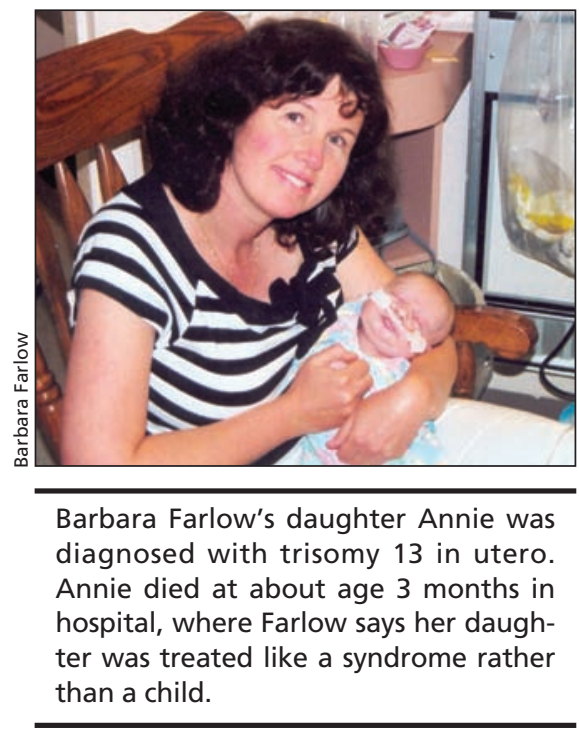

Microarray testing has already been used extensively as a diagnostic tool in pediatrics. When used to identify the genetic roots of mental retardation in children, for instance, it has proven twice as effective as conventional techniques. Researchers say it may be even more useful for prenatal diagnosis, detecting up to 200 genetic abnormalities, while returning ambiguous results in only $1 \%$ of cases. Proponents of the test also point out that it can be performed earlier than amniocentesis and that it provides the maximum amount of information about a fetus, allowing a prospective parent to either terminate the pregnancy or prepare for a child with disabilities.

"For detecting fetal abnormalities, there is no doubt that microarray is a very useful technique," says Dr. Doug Wilson, who heads the Department of Obstetrics and Gynecology at the University of Calgary, in Calgary, Alberta.

Some genetic researchers believe it is premature to promote widespread use of microarray testing. The chromosomal imbalances that the test detects are so subtle that interpreting their significance is difficult. Doctors cannot tell their patients definitively if some detected anomalies are benign or pathogenic. They will not necessarily know the impact of an abnormality, or its severity, if one exists. Will fetuses with relatively minor genetic defects - an increased risk for cancer, say, or a predisposition toward obesity — be regularly aborted?

"This detects way more than has ever been detected before, and has moved from research to clinical practice very quickly," says Dr. Jan Friedman, professor of medical genetics at the University of British Columbia in Vancouver, British Columbia.

Friedman recognizes the strengths of microarray testing but warns that nobody's DNA, when you dig deep enough, is perfect. Subtle genetic variations are normal and often harmless. Friedman recommends that the technology only be used, at least for now, in clinical trials or for pregnancies in which fetuses are at high risk of having chromosomal abnormalities. Because couples can terminate a pregnancy early in the term for any reason, Friedman says, doctors will be dealing with that issue more if microarray testing becomes popular, and they should not ignore the effects of dropping mountains of genetic data onto people's laps. "It behooves us to give this some thought before we reach that point."

If the test does become commonplace - and it soon will, according to some geneticists - providing good genetic counselling to expectant parents will be crucial. Understanding complex and sometimes ambiguous genetic information is no easy task. Many people don't even know the difference between risk and diagnosis. The primary challenge that microarray testing will present, however, may not be understanding the data but just getting through it.

"For me, the difference is the volume of the information you are getting," says Chris Trevors, board secretary of the Canadian Association of Genetic Counsellors. "People look for health care providers to guide them on how to interpret this info, and if we can't,
I don't think we should be offering it."

Then there are the ethical concerns. Medical ethicists and disability rights advocates question the motivations behind promoting microarray testing. There are no treatments for many of the genetic disorders the test will uncover. That leaves termination as the only option for parents who don't want disabled children. Disability support groups cite the effect of prenatal screening for Down syndrome as the most ominous example - the number of children born with the condition dropped by almost 90\% when screening for it became widespread. Do we want a society, some ask, in which disabled people will eventually be found only in history books?

"There's a biological imperative for diversity. If we eliminate things like Down syndrome, what else is next?" asks Krista Flint, executive director of the Canadian Down Syndrome Society.

Advocates for the test say expectant parents can never be too informed and that more knowledge empowers people to make better choices. But detractors warn that it's folly to ignore the collective impact of individual choices and that nothing good has ever come from the scientific pursuit of human perfection.

"Are we on a search-and-destroy mission for babies that don't measure up?" asks ethicist Margaret Somerville, Samuel Gale Professor of Law at McGill University in Montréal, Quebec.

Some claim doctors favour microarray testing because it provides better protection against wrongful-birth lawsuits, which ethicists say is an inappropriate benchmark for setting standards of care. Evelyne Schuster, medical ethicist at the University of Pennsylvania, in Philadelphia, Pennsylvania, has said that normality cannot be established at the molecular level. Adrienne Asch, director of the Center for Ethics at Yeshiva University, in New York, has expressed concern that a time will come when all parents genetically audition their fetuses to determine if they are worthy of life.

"Is this a new eugenics?" asks Somerville. "I think it is." - Roger Collier, CMAJ

DOI:10.1503/cmaj.090349 